\title{
The role of particulate guanylyl cyclase B (GC-B) in auditory function in adult mice
}

\author{
Steffen Wolter ${ }^{1 *}$, Dorit Möhrle ${ }^{1}$, Dennis Zelle ${ }^{1}$, Marlies Knipper ${ }^{1}$, Hannes Schmidt ${ }^{2}$, Lukas Rüttiger ${ }^{1}$ \\ From 7th International Conference on cGMP Generators, Effectors and Therapeutic Implications \\ Trier, Germany. 19-21 June 2015
}

\begin{abstract}
Background
cGMP signaling triggered by the binding of C-type natriuretic peptide (CNP) to its receptor guanylyl cyclase B (GC-B; NPR2; NPRB) has been linked by genetic evidence to a remarkable variety of physiological functions like skeletal bone growth, female fertility, cardiac growth, fat metabolism and gastrointestinal function. For the nervous system it has been recently demonstrated that the CNP/GC-B/cGMP/cGMP-dependent protein kinase type I (cGKI) signaling pathway is essential for sensory axon branching at the dorsal root entry zone of the spinal cord and at the rhombomeres of the hindbrain during embryonic development [1]. Also in the auditory system, distinct auditory nerve fiber (ANF) types that differ in their discharge rate and sound sensitivity bifurcate in the cochlear nucleus $(\mathrm{CN})$, sending collaterals to the anteroventral, posteroventral, and dorsal subdivisions. The lack of GC-B has been shown to lead to a central phenotype [2].
\end{abstract}

\section{Results}

Here, we describe that the lack of GC-B in addition leads to a peripheral phenotype which is manifested in auditory threshold loss and altered wave amplitudes and latencies of stimulus-evoked auditory brainstem responses (ABR). Our preliminary results indicate that this deficit is related to a combined afferent and efferent fiber phenotype.

\section{Outlook}

We will further investigate the functional consequences of bifurcation loss of ANF on central hearing function and central plasticity. This may lead to sound localization problems, a progressive aging phenotype [3] and an increased risk for tinnitus [4].

\section{Acknowledgement}

This work was supported by grants from the Deutsche Forschungsgemeinschaft (FOR 2060 project FE 438/5-1).

\section{Authors' details}

'University of Tübingen, Department of Otolaryngology, Tübingen, Germany. ${ }^{2}$ Max Delbrück Center for Molecular Medicine, Developmental Neurobiology, Berlin, Germany.

Published: 2 September 2015

\section{References}

1. Ter-Avetisyan G, Rathjen FG, Schmidt H: Bifurcation of axons from cranial sensory neurons is disabled in the absence of Npr2-induced cGMP signaling. J Neurosci 2014, 34(3):737-747.

2. Lu CC, Cao XJ, Wright S, Ma L, Oertel D, Goodrich LV: Mutation of Npr2 leads to blurred tonotopic organization of central auditory circuits in mice. PLoS Genet 2014, 10(12):e1004823.

3. Sergeyenko Y, Lall K, Liberman MC, Kujawa SG: Age-related cochlear synaptopathy: an early-onset contributor to auditory functional decline. J Neurosci 2013, 33(34):13686-13694.

4. Knipper M, Van Dijk P, Nunes I, Rüttiger I, Zimmermann U: Advances in the neurobiology of hearing disorders: recent developments regarding the basis of tinnitus and hyperacusis. Prog Neurobiol 2013, 111:17-33.

doi:10.1186/2050-6511-16-S1-A102

Cite this article as: Wolter et al:: The role of particulate guanylyl cyclase

$\mathrm{B}$ (GC-B) in auditory function in adult mice. BMC Pharmacology and

Toxicology 2015 16(Suppl 1):A102.

* Correspondence: steffen.wolter@uni-tuebingen.de

1 University of Tübingen, Department of Otolaryngology, Tübingen, Germany

Full list of author information is available at the end of the article 